\title{
AN INTRACELLULAR STRUCTURE IN BACTEROIDES FRAGILIS
}

\author{
J. H. REID \\ Department of Microbiology and Immunobiology, The Queen's University of Belfast, Grosvenor \\ Road, Belfast BT12 6BN, Northern Ireland
}

\section{Plate XIX}

SUMmaRY. An unusual intracellular circular or oval structure was discovered during a morphological study of Bacteroides fragilis by electronmicroscopy. The structure is complex, composed of multiple concentric layers surrounding a central region. The dimensions and profile are consistent in all the sections observed. The sections illustrated may represent various stages in the morphogenesis of the complete structure.

\section{INTRODUCTION}

A recent morphological investigation of Bacteroides fragilis ATCC 23745 by transmission electronmicroscopy has revealed a complex intracellular structure which has not been reported previously.

\section{MATERIALS AND METHODS}

Organism. Bacteroides fragilis ATCC23745 was obtained in lyophilised form from the American Type Culture Collection. The organism was cultured anaerobically on $5 \%$ laked human-blood agar made with Oxoid Blood Agar Base No. 2.

Baird and Tatlock anaerobic jars with two catalyst sachets per jar and side-arm manometers were used to maintain an anaerobic atmosphere of $90 \% \mathrm{H}_{2}$ and $10 \% \mathrm{CO}_{2}$. Primary subcultures were used for inoculation of basal medium (Deacon, Duerden and Holbrook, 1978) which was incubated anaerobically for $18 \mathrm{~h}$ at $37^{\circ} \mathrm{C}$, and $5-\mathrm{ml}$ volumes were then dispensed into sterile containers and stored at $-20^{\circ} \mathrm{C}$. These stock cultures were thawed and used for inoculation of basal media which were incubated in anaerobic conditions for $18 \mathrm{~h}$ at $37^{\circ} \mathrm{C}$ to provide the cultures for examination.

Preparation of specimens for electronmicroscopy. Ruthenium red (Sigma Chemical Company, London) was purified according to the method of Luft (1971). A $0.7 \%$ solution of purified stain was made in $0 \cdot 2 \mathrm{M}$ cacodylate buffer at $p \mathrm{H} 6 \cdot 5$. Bacteria were harvested from $18-\mathrm{h}$ broth cultures and resuspended in $1 \mathrm{ml}$ of the ruthenium-red solution to which was added an equal volume of $3.6 \%$ glutaraldehyde. Fixation was done at $4{ }^{\circ} \mathrm{C}$ for $1 \mathrm{~h}$, after which the bacteria were washed in three changes of $0.1 \mathrm{M}$ cacodylate buffer at $p \mathrm{H} 6.5$, resuspended in $1 \mathrm{ml}$ of ruthenium-red solution containing $1 \%(\mathrm{v} / \mathrm{v})$ osmium tetroxide and incubated for $3 \mathrm{~h}$ at $22^{\circ} \mathrm{C}$ in the dark. The bacteria were dehydrated in graded ethyl alcohols, embedded and sectioned for electronmicroscopy, stained with uranyl acetate and lead citrate and viewed in a Philips 301 transmission electronmicroscope.

\section{RESULTS}

The structure observed is found in terminal, subterminal or central positions within the

Received 28 Nov. 1980; accepted 29 Dec. 1980. 
bacterial cell and may occur singly or in closely associated pairs. It occurs with low frequency in the populations examined.

The complete structure is complex, circular or oval, with multiple concentric layers enclosing a central region (fig. 1). The outermost layer is well defined, of uniform thickness $(5 \mathrm{~nm})$ and has a cross-hatched appearanced (fig. 2). There is a second diffuse layer of similar electron density in close association with the outer layer but separated from it by a narrow non-electron-dense region.

The remainder of the structure is separated from the outermost layers by a non-electrondense region across which there are fine strands. The central region of the structure is surrounded by two concentric parallel electron-dense layers. Adjacent to the innermost of these layers and surrounding the core is a diffuse heavily stained region. The composition of the core is comparable to the cytoplasm and three or four electron-dense components have been visualised within this region (figs. 2 and 3 ).

A variety of stages with the same dimensions and characteristic morphological profile ranging from crescent shape through semicircular to a complete circular or oval structure have been visualised (figs. 2-4). No association between the cytoplasmic membrane and the structure has been observed, and this structure has not been detected as a free body independent of the vegetative cell.

This intracellular structure has been observed in three different preparations of $B$. fragilis ATCC23745. Similar observations have been made on studies of $B$. fragilis NCTC10581.

\section{DISCUSSION}

The laminar structure of this intracellular body is not comparable with that of the cell wall and membranes of the organism, and therefore is most unlikely to be the result of invagination of the cell envelope. B. fragilis ATCC 23745 was originally called Sphaerophorus intermedius by Bergan and Hovig (1968), who observed spheroid elements in the organism. However, the dimensions of the structures observed by these workers are not comparable with those of the structure described here.

The multilayered structure in some respects resembles a spore. However, there is no evidence of any association between the cytoplasmic membrane and the structure described, as is characteristic of sporulation in Bacillus and Clostridium species. The bacteroides group of organisms are by definition non-sporing gram-negative anaerobic bacilli, which would preclude this possible explanation.

The electronmicrographs (figs. 1-4) are sections through different organisms but may represent stages in the morphogenesis of the structure in which the various layers are formed concurrently, eventually resulting in a spherical or oval intracellular structure.

Dr Evelyn Dermott's contributions of helpful discussion and instruction in electronmicroscopic techniques were invaluable.

\section{REFERENCES}

Bergan, T. AND Hovig, B. 1968. A new species, Sphaerophorus intermedius, isolated from empyema. Acta path. microbiol. scand., 74, 421.

Deacon, A. G., Duerden, B. I. ANd Holbrook, W. P. 1978. Gas-liquid chromatographic analysis of metabolic products in the identification of Bacteroidaceae of clinical interest. $J$. med. Microbiol., 11, 81 .

LuFT, J. H. 1971. Ruthenium red and ruthenium violet. 1. Chemistry, purification, methods of use for electron microscopy and mechanism of action. Anat. Rec., 171, 347. 
INTRACELLULAR STRUCTURE OF $B$. FRAGILIS
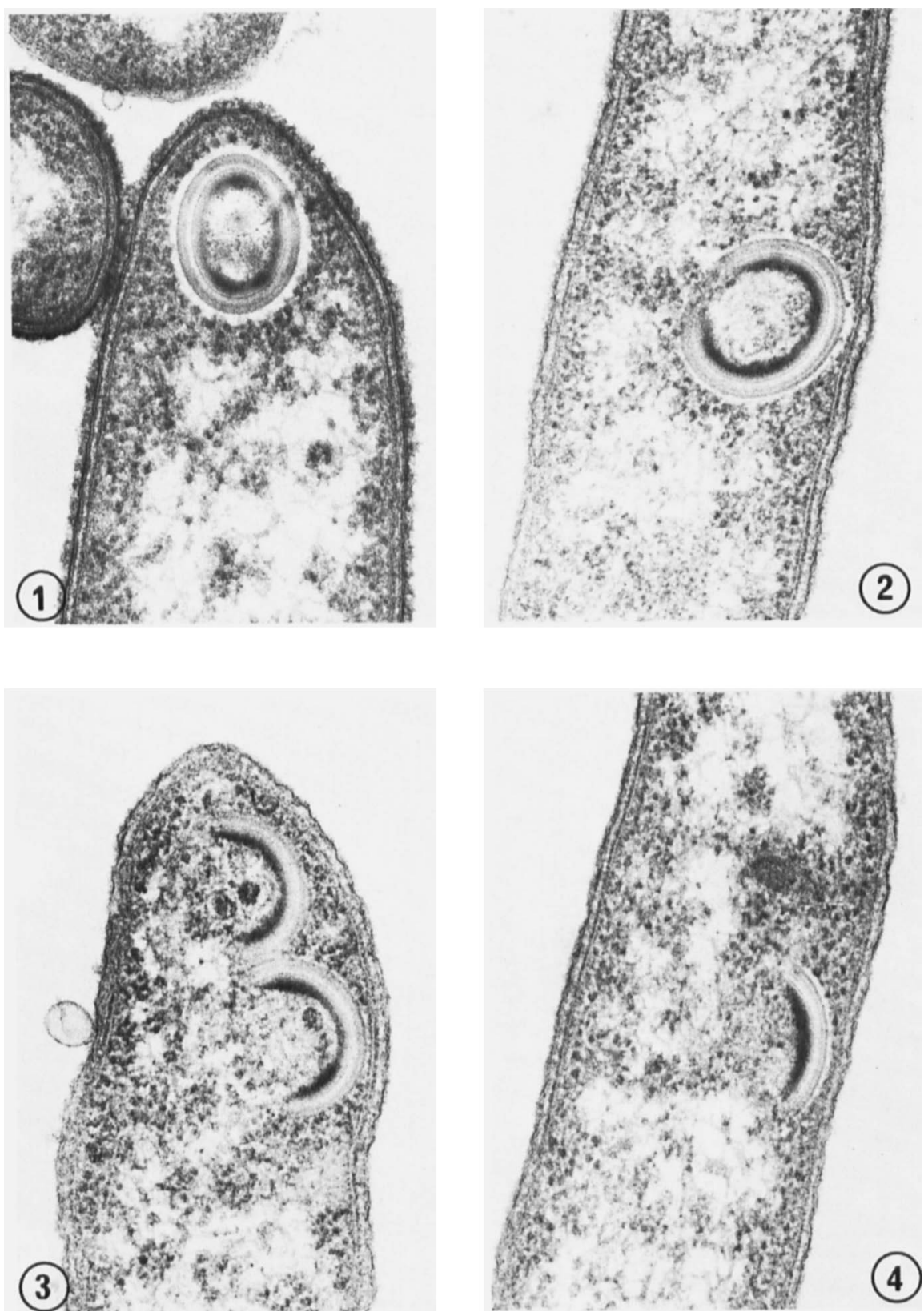

FIGS. 1-4.-Electronmicrographs of Bacteroides fragilis showing intracellular structures. $\quad \times 100000$ 
